\title{
... And Wile E. Coyote Caught the Road Runner
}

Near the dawn of time, the story goes, Coyote saved the creatures of Earth. According to the mythology of Idaho's $\mathrm{Nez}$ Perce people, the monster Kamiah had stalked into the region and was gobbling up the animals one by one. The crafty

Coyote evaded Kamiah but did not want to lose his friends, so he let himself be swallowed. From inside the beast, Coyote severed Kamiah's heart and freed his fellow animals. Then he chopped up Kamiah and threw the pieces to the winds, where they gave birth to the peoples of the planet. ${ }^{1(\mathrm{p} .296)}$

The reason that the ordinary Wile E. Coyote has managed to succeed (ie, survival and reproduction in the animal kingdom) where many other creatures have suffered is likely his incredible capacity of adaptation. ${ }^{1}$ This includes, over the past 2 centuries, changes in body dimensions, metabolism, and diet that allowed him to survive and have more offspring in new regions under varying terrains and climate, from the prairies of central North America to farms in Mexico or even Rock Creek Park in Washington State! Put differently, the coyote stands out as the master of adaptationand I use this example of microevolution to comment on our practices in business, elite sport, and academia.

In reality, the determinants of a successful career in our modern world are not very far from the theory of evolution. While the "survival of the fittest" analogy may be a bit extreme, the ability to adjust an organization's internal systems to conform to other external environmental factors such as raw material availability and economic variables is a necessity for business people, entrepreneurs, or managers. Adaptation is believed to be compulsory for business sustainability and likely reduces the risk of suffering an organizational crisis. In elite sports, practitioners' ability to adapt their behavior and actions to the context they operate in is mandatory to deliver top programs and maintain fit and healthy athletes. ${ }^{2}$ Most people who have worked in the elite performance setting for more than a few years would agree that what makes them successful (or not) often has nothing to do with what they learned at school. ${ }^{2}$ In other terms, an individual's knowledge and skill set are rarely the most important assets making them a good or a bad practitioner. While a minimum level of (academic) qualification is obviously needed, real-time capacity to adapt to a new/specific situation ${ }^{3}$ and the application of pragmatism ${ }^{4}$ are by far more valued attributes in the high-performance setting. ${ }^{5}$ At the personal level also, the ability to organize our daily rituals around short- and long-term goals and immediate context is required to meet work deadlines and preserve a balanced social life. ${ }^{6}$ Overall, combined with a type III archetype (opened minded, proactive, and driven), ${ }^{7}$ coyote-type practitioners likely present the best personal traits to succeed in business, life, and elite performance.

As far as academic research is concerned, the same reasoning applies. How many times have I received e-mails from young sport scientists asking for directions for their research (ie, "What shall I study?")? Most of the time, my response is, "It depends on your context!" In fact, there are likely as many research foci and strategies as there are sport scientists and research groups, since most of the time the questions to be answered, the cohort or population

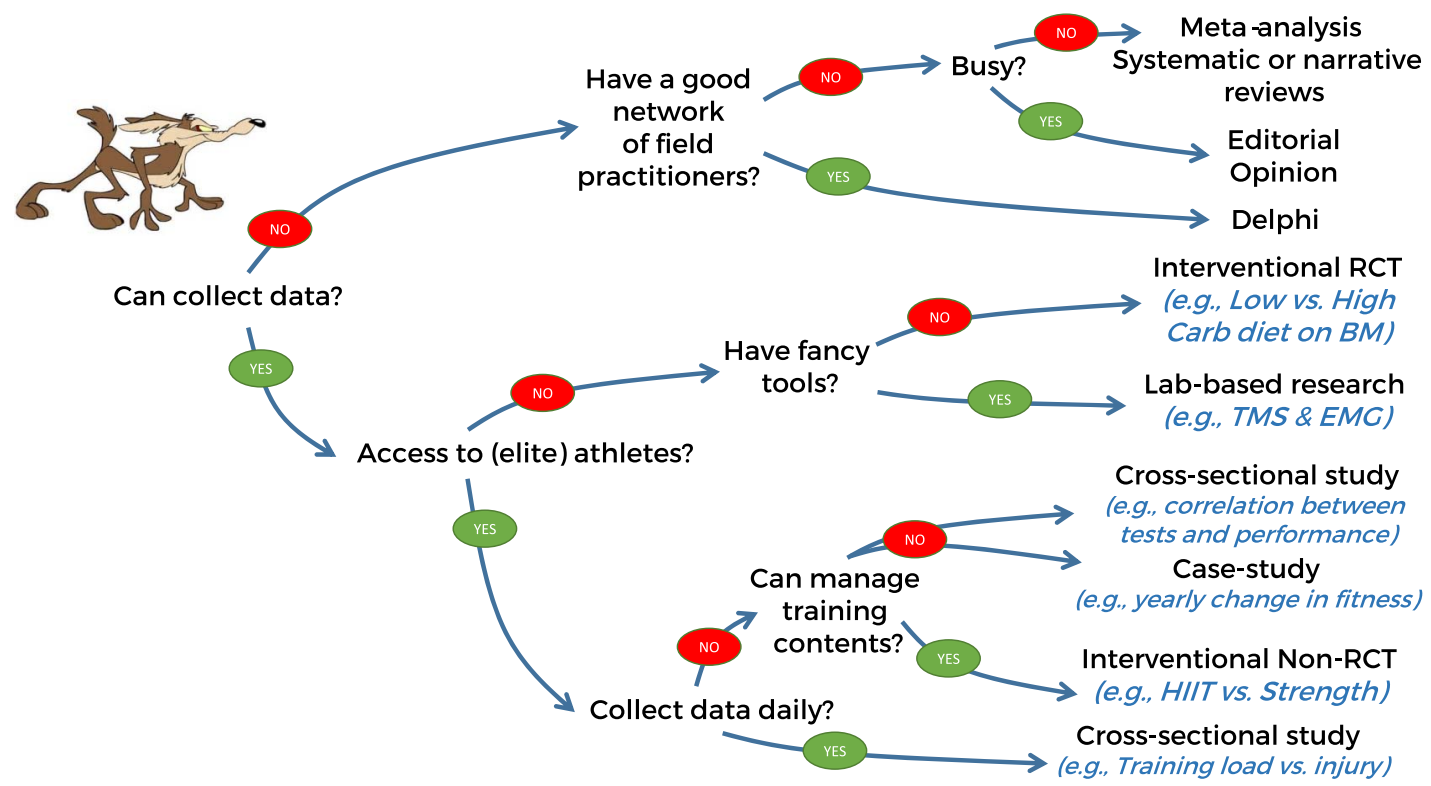

Figure 1 - Decision tree for selecting the most appropriate research strategy as a function of the context, that is, adapting research means and focus to data availability, population, and tools available. Note that while an RCT can obviously also be performed when researchers have fancy tools, without tools it becomes very difficult to publish if the study design is not advanced (ie, favoring interventional study, and RCT if possible). BM indicates body mass; EMG, electromyography; RCT, randomized controlled trial; TMS, transcranial magnetic stimulation. Wile E. Coyote image licensed via carlos cardetas/Alamy Stock Photo. 
to study, the facilities and tools at disposal, and the analytical methods mastered vary dramatically. So, how do we choose what to research? By knowing which questions need to be answered, ${ }^{8}$ of course, but adaptation to context and using pragmatism are clearly important too. No need for all to publish in Experimental Physiology, but not all in International Journal of Sports Physiology and Performance either! Difficulties in recruiting subjects? Limited by budget to buy fancy enzyme analyzers or transcranial magnetic stimulators? Let's conduct a systematic review or a meta-analysis, which has the advantage of standing on the top of the pyramid of the evidence ${ }^{9}$ while not requiring any practical investigation. Can't collect data yourself for some reason? Partner with another university, research institute, sporting organization, or a club and offer help with the analytics and writing. ${ }^{8}$ Can't get access to elite athletes and monitor their load daily? Work on training responses or injury surveillance. As shown in Figure 1, there is likely an optimal scenario for each researcher in relation to his or her specific context. The point I make here is that often researchers may gain advantage from researching what they can and what matters (as discussed in depth previously ${ }^{2,8}$ ), rather than what they want. To seize the best publication opportunities, young sport scientists may need to prepare themselves and develop a wide range of academic skills (eg, knowledge of different study designs, technology, data analysis, statistics, writing, and referencing) that will enable them to adapt their investigations and focus on the right research projects - in relation to the type of data available and the useful questions that can be answered with those materials (Figure 1). If research and publishing are our main jobs, how could we afford to not optimize all these processes?

In the business, elite-sport, or academic setting, there is never only one way to complete a task, but there is usually a better way-or a least-bad option-for a given context. ${ }^{7}$ Our old friend Wile E. Coyote has taught us that the determinants of success are not likely in the knowledge and the skills per se but, rather, in our capacity to adapt our behavior and actions (often on the fly) to suit a specific situation. That is how he finally caught the Road Runner!

Martin Buchheit, Associate Editor, IJSPP

\section{References}

1. Levy S. Rise of the coyote: the new top dog. Nature. 2012; 485(7398):296-297. PubMed ID: 22596135 doi:10.1038/485296a

2. Buchheit M. Chasing the 0.2. Int J Sports Physiol Perform. 2016; 11(4):417-418. PubMed ID: 27164725 doi:10.1123/ijspp.2016-0220

3. Buchheit M. Content is king, but context is god. HIIT Science Blog. 2018. https://hiitscience. Com/content-is-king-but-context-is-god/

4. Buchheit M. The hands that help are far better than lips that pray. HIIT Science Blog. 2018. https://hiitscience. Com/the-hands-that-help-arefar-better-than-lips-that-pray/

5. Jovanovic M. High Intensity Interval Training and Agile Periodization. Thome M, Mann JB, Eds. Muskegon, MI: Ultimate Athlete Concepts; 2018

6. Buchheit M. Daily morning rituals, making or ruining the day? HIIT Science Blog. 2018. https://hiitscience. Com/daily-morning-ritualswinning-or-ruining-the-day/

7. Buchheit M. Outside the box. Int J Sports Physiol Perform. 2017;12(8):1001-1002. PubMed ID: 29091528 doi:10.1123/IJSPP. 2017-0667

8. Buchheit M. Houston, we still have a problem. Int J Sports Physiol Perform. 2017;12(8):1111-1114. PubMed ID: 28714760 doi:10. 1123/ijspp.2017-0422

9. Harbour R, Miller J. A new system for grading recommendations in evidence based guidelines. BMJ. 2001;323(7308):334-336. PubMed ID: 11498496 doi:10.1136/bmj.323.7308.334 